\title{
Formation of Cortical Fields on a Reduced Cortical Sheet
}

\author{
Kelly J. Huffman, ${ }^{1}$ Zoltán Molnár, ${ }^{2,3}$ Anton Van Dellen, ${ }^{2}$ Dianna M. Kahn, ${ }^{1}$ Colin Blakemore, ${ }^{2}$ and \\ Leah Krubitzer ${ }^{1}$ \\ ${ }^{1}$ Center for Neuroscience and Department of Psychology, University of California, Davis, Davis, California 95616, \\ 2University Laboratory of Physiology, University of Oxford, England OX1 3PT, and 3/nstitut de Biologie Cellulaire et de \\ Morphologié Faculté de Medecine, 1005 Lausanne, Switzerland
}

Theories of both cortical field development and cortical evolution propose that thalamocortical projections play a critical role in the differentiation of cortical fields (O'Leary, 1989; Krubitzer, 1995). In the present study, we examined how changing the size of the immature neocortex before the establishment of thalamocortical connections affects the subsequent development and organization of the adult neocortex. This alteration in cortex is consistent with one of the most profound changes made to the mammalian neocortex throughout evolution: cortical size. Removing the caudal one-third to three-fourths of the cortical neuroepithelial sheet unilaterally at an early stage of development in marsupials resulted in normal spatial relationships between visual, somatosensory, and auditory cortical fields on the remaining cortical sheet. Injections of neuroanatomical tracers into the reduced cortex revealed in an altered

The mammalian cerebral cortex is composed of separate cortical fields that have distinct architectonic appearances, patterns of connectivity, and physiological properties (Brodmann, 1909; Kaas, 1982). How these fields develop and how development is altered in different mammalian lineages to generate the remarkable variation in brain size and cortical field number is fundamental to understanding how brains are constructed in evolution. One approach to unraveling this mystery is to examine the products of the evolutionary process to determine common patterns of brain organization as well as to identify modifications to this common plan. By comparing neocortical organization across species, it is possible to gain insights into the constraints imposed on the developing nervous system that limit the types of modifications that can be made to existing patterns of organization (Krubitzer, 1995).

A second approach to understanding brain evolution is to examine the developmental process itself (Killackey, 1990; Wray, 1994). By investigating the developmental mechanisms that account for the existing organization of the neocortex in extant mammals, we can infer how homologous developmental processes

Received June 30, 1999; revised Sept. 3, 1999; accepted Sept. 3, 1999.

This project was supported by grants to Leah Krubitzer from National Institutes of Health (1R01 NS35103-01A1) and the Whitehall Foundation (M97-20), and by a Novartis Bursary award, a McDonnell Pew Centre for Cognitive Neuroscience Oxford, North American Network grant to Zoltán Molnár, and a Leverhulme research grant and a Medical Research Council Grant (G9320738) to Colin Blakemore. We thank Ken Britten, Barbara Chapman, Bruno Olshausen, and Gregg Recanzone for helpful comments on this manuscript.

Correspondence should be addressed to Leah Krubitzer, Center for Neuroscience, 1544 Newton Court, Davis, California 95616. E-mail: lakrubitzer@ucdavis.edu.

Copyright (C) 1999 Society for Neuroscience $0270-6474 / 99 / 199939-14 \$ 05.00 / 0$ distribution of thalamocortical axons; this alteration allowed the maintenance of their original anteroposterior distribution. These results demonstrate the capacity of the cortical neuroepithelium to accommodate different cortical fields at early stages of development, although the anteroposterior and mediolateral relationships between cortical fields appear to be invariant. The shifting of afferents and efferents with cortical reduction or expansion at very early stages of development may have occurred naturally in different lineages over time and may be sufficient to explain much of the phenotypic variation in cortical field number and organization in different mammals.

Key words: cerebral cortex; visual cortex; cortical organization; development; evolution; electrophysiology; Monodelphis domestica

have been modified to yield the differences in cortical organization observed across mammals.

Comparative work has demonstrated that one of the most dramatic changes to the neocortex is an increase in the size of the cortical sheet (Kaas, 1982; Ridgway, 1986; Kaas, 1988; Stephan et al., 1988; Krubitzer, 1995; Manger et al., 1998). This change is associated with an increase in cortical field number and has led us to question how changing the size of the developing cortical sheet would affect the subsequent cortical organization.

Currently, there is some dispute over when cortical fields are differentiated in development and how cortical fields are specified. One proposition is that cortical fields can begin the process of compartmentalization very early in development in the ventricular zone, well before cortical neurons are born and before any connections are made (Rakic, 1988; DeHay et al., 1993; Polleux et al., 1997a,b) (for review, see Levitt et al., 1995; Rakic, 1995b). A second view is that the developing neocortex is unspecified, to a large extent, and that connections from the thalamus and other sources contribute to cortical field generation (Chang et al., 1986; O'Leary, 1989; Killackey, 1990; Roe et al., 1990; Molnár and Blakemore, 1991, 1995; Schlaggar and O'Leary, 1991; O'Leary et al., 1994). Although these theories are historically relevant and allow us to formulate testable hypotheses regarding the laminar and tangential differentiation of the cerebral cortex, neither explanation of cortical field specification is likely to be exclusive. Rather, some combination of early regional differentiation as well as thalamic afferent contribution is ultimately responsible for cortical field differentiation in development and the resultant cortical organization in adults (for review, see O'Leary et al., 1994). 

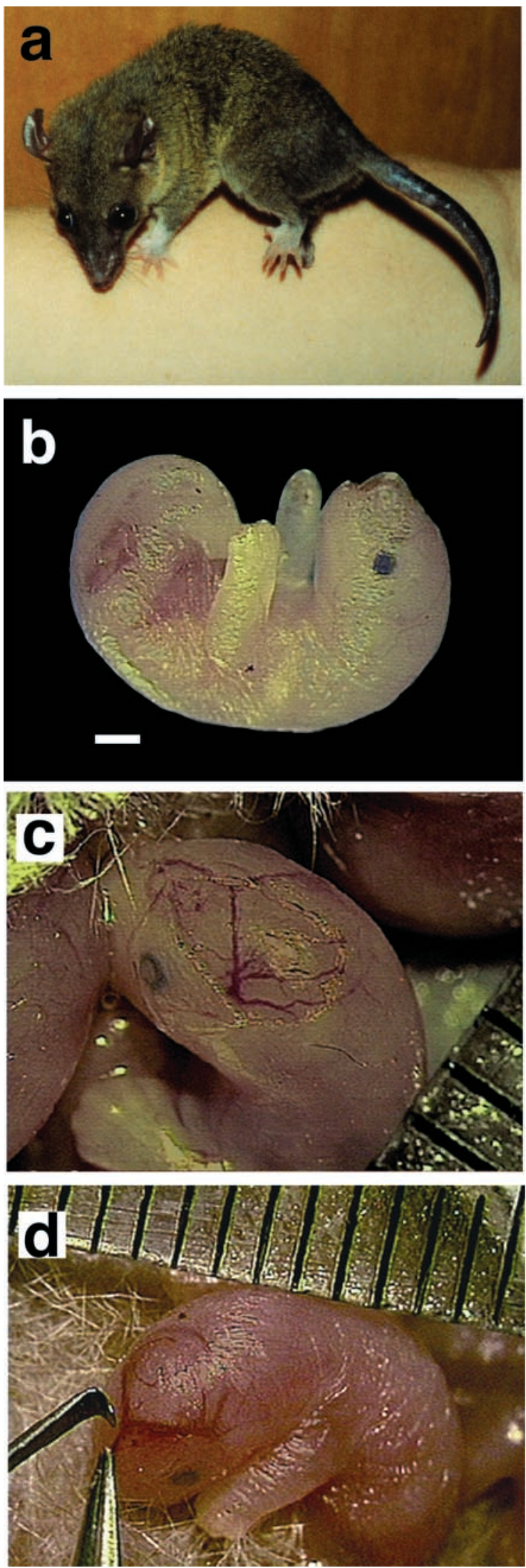

Figure 1. Photograph of an adult short-tailed opossum, Monodelphis domestica $(a)$, and a P4 infant $(b)$. To document the surgical procedures, a CCD camera (Optronics) was used to produce digital images of the P4 infants while they were attached to the mother's nipple during our
To examine the contribution of developing thalamocortical afferents to cortical field specification, we removed a large portion of the cortical neuroepithelium in Monodelphis domestica before the arrival of thalamocortical afferents, which occurs at postnatal day 7 (P7) (Molnár et al., 1998). On the basis of our observations from comparative studies, along with a wealth of studies on cortical development, we predicted that the removal of a relatively large portion of the cortical neuroepithelial sheet would not abolish cortical fields that normally reside in the removed cortex. Rather, such a manipulation might result in the emergence of cortical fields and thalamic afferents in appropriate geometric alignment on the remaining cortical sheet. A different possible outcome would be the loss of certain cortical fields, without substantially affecting any other cortical fields or related thalamic nuclei (Cunningham et al., 1987).

In the series of experiments reported here, we removed a large portion of the immature neocortex in Monodelphis domestica at P4 (see Fig. 1b), which corresponds to embryonic day 14 (E14) in rats (Molnár et al., 1998). In the adult manipulated animals, electrophysiological recordings, neuroanatomical connections, and architectonic analyses were used to assess the organization and thalamocortical connections of the remaining cortex.

Preliminary results from this study have been published previously (Huffman et al., 1998; Krubitzer et al., 1998).

\section{MATERIALS AND METHODS}

Animals. Four days after birth (P4), two adult Monodelphis domestica mothers (Fig. 1a) were immobilized with an initial dose of alphaxalone $(45 \mathrm{mg} / \mathrm{kg})$ and alphadolone $(15 \mathrm{mg} / \mathrm{kg})$; this anesthetic does not pass into the mother's milk. Subsequent doses of one-half of the initial dose were given as needed to maintain anesthesia. The individual young (Fig. $1 b)$ were anesthetized hypothermically by placing ice on each pup just before surgery. Once anesthetized, the skin over the skull was cut and retracted (Fig. 1c), the developing skull was cut, and between one-third and three-fourths of the posterior cortical neuroepithelium was manually excised unilaterally under microscopic guidance using microsurgical instruments (Fig. 1d). The skull flap was repositioned, and the skin was held in place with Nexaband (Veterinary Products Laboratories, Phoenix, AZ). The initial manipulations were performed under aseptic conditions, and the chronic surgery in adults was performed under standard sterile conditions. All experimental protocols were approved by the Animal Use and Care Administrative Advisory Committee of the University of California, Davis.

Of the two litters in which P4 animals were manipulated, one mother cannibalized the young, a behavior that is common in these animals in captivity. In the one remaining litter, four animals were used for electrophysiological recording, and one animal was used for studying thalamocortical connections. Experiments were conducted 8-12 months after the initial P4 manipulations. A total of 9 normal animals were used to study the functional organization $(n=6)$ and connections $(n=3)$ of the cortex, and three normal animals were used for volumetric measurements of the diencephalon (see below).

After the animals reached adulthood, the neocortex was surveyed using multiunit electrophysiological recording techniques, similar to those used to identify the location and internal organization of cortical fields in various mammals (Krubitzer et al., 1993). By delineating stimulus preference, receptive field size, and receptive field configuration, we could subdivide the neocortex into separate cortical fields (Huffman et al., 1999). In one of the animals, the thalamocortical connections of the reduced neocortex were investigated by placing the fluorescent tracers diamidino yellow (DY) + nuclear yellow (NY), fluororuby (FR), and

procedure $(c)$. A midline incision was made, and the skin and skull were retracted in preparation for the cortical neuroepithelial reduction. After the lesion was made with the excision tool $(d)$, the skin was repositioned with forceps and held together with glue. Scale bar, $1 \mathrm{~mm}$ 

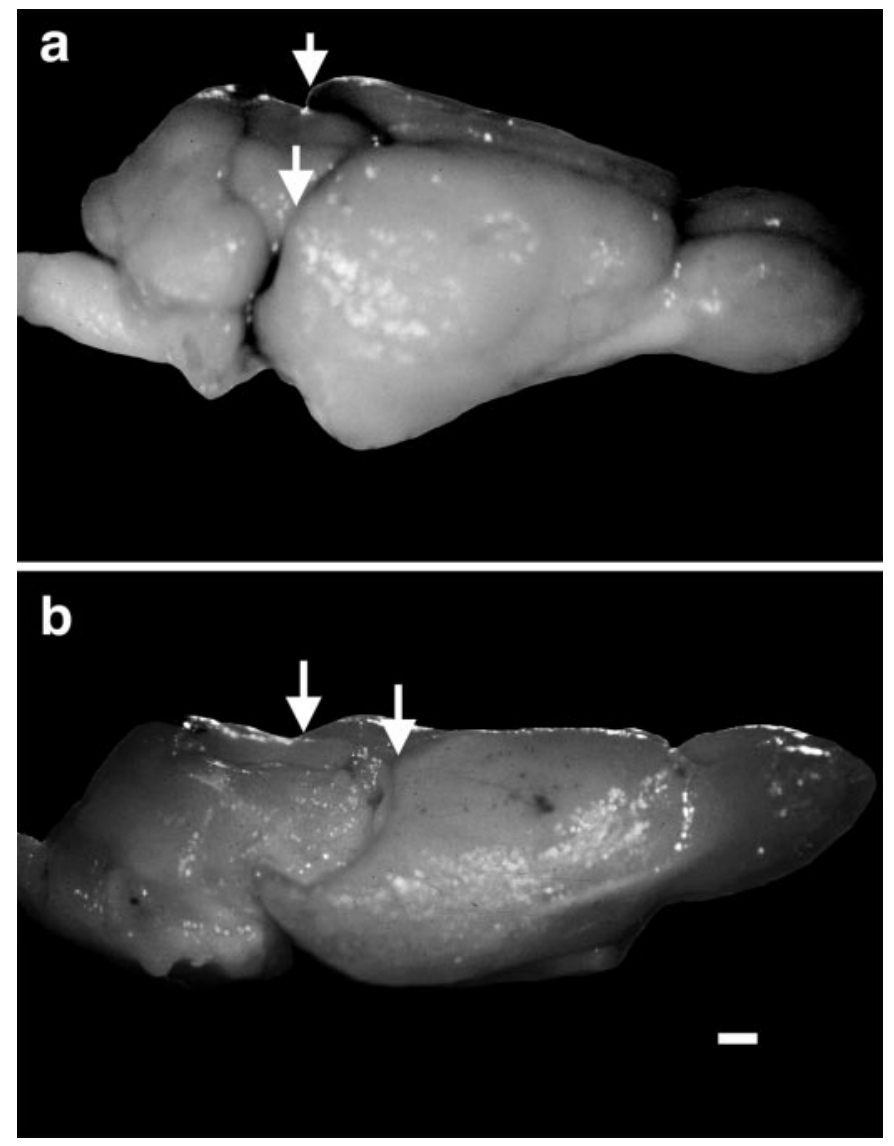

Figure 2. $a$, Photograph of a lateral view of the brain of a normal adult short-tailed opossum and $(b)$ an adult short-tailed opossum that had the caudal one-third of the right developing neocortex removed at P4. The arrows in both figures indicate the caudal pole of each hemisphere in the normal cortex and the manipulated cortex. Note that the caudal pole of the remaining cortex $(b)$ is far rostral to its location in the normal animal and compared with the opposite hemisphere. Rostral is to the right, and dorsal is to the top. Scale bar, $1 \mathrm{~mm}$.

fluoroemerald (FE) into the neocortex and identifying retrogradely labeled cell bodies in the thalamus.

For electrophysiological recording experiments the animals were anesthetized with ketamine hydrochloride $(40 \mathrm{mg} / \mathrm{kg}$, i.m.), xylazine (5 $\mathrm{mg} / \mathrm{kg}$, i.m.), and sodium pentobarbital ( $20 \mathrm{mg} / \mathrm{kg}$, i.p.). Once anesthetized, the dorsal surface of the neocortex was completely exposed, and digital images of the exposed cortex were printed so that recording sites could be matched to blood vessel patterns. Tungsten electrodes $(5 \mathrm{M} \Omega)$ designed to record from small cell clusters were lowered into the brain at a depth of 200-400 $\mu \mathrm{m}$ at a number of closely spaced recording sites. At each site, sensory stimulation consisted of small indentations of the glabrous and hairy skin with fine probes, light brushing of the glabrous skin, displacing of hairs, and hard taps to the skin and body for somatosensory stimulation. For visual stimulation, full-field flashes of light, moving bars of light, and flickering light were used to evoke neural responses. Clicks and high-frequency taps produced by tapping metal or wood objects together were used for auditory stimulation. After the completion of experiments, probes were placed in the cortex at several locations for later identification in histologically processed tissue.

For neuroanatomical tracing experiments, the animals were anesthetized as describe above, and then $0.3 \mu \mathrm{l}$ of $7 \% \mathrm{FE}$ and of $7 \% \mathrm{FR}$ were injected into the neocortex. The DY plus NY were placed in the neocortex as crystals (Krubitzer et al., 1993). The animals were allowed to survive for 1 week for transport of tracers.

After the completion of both the electrophysiological recording experiments and neuroanatomical tracing experiments, the animals were perfused with $0.9 \%$ saline, followed by $3 \%$ paraformaldehyde in phosphate buffer, $\mathrm{pH} 7.4$, and then $3 \%$ paraformaldehyde in $10 \%$ sugar phosphate buffer. When perfusion was complete, the brains were removed from the cranium and immersed in $30 \%$ sugar phosphate buffer overnight. The brains were sectioned coronally on a freezing microtome into $50-60 \mu \mathrm{m}$ sections and alternately stained for Nissl substance, cytochrome oxidase (CO) (Carroll and Wong-Riley, 1984), and in some cases myelin (Gallyas, 1979). In the case in which injections of neuroanatomical tracers were made, an alternate series of sections was mounted for fluorescent microscopy.

Histological and electrophysiological data analysis. In all cases, digital images of the brain in which electrode tracks and probes were marked were correlated with histologically processed tissue. By examining receptive field progressions for neurons in somatosensory cortex and delineating different territories that represented different types of sensory input, maps of the cortex were made, and in normal animals they were related to architectonic boundaries (Huffman et al., 1999). For the four cases with early lesions, the physiological maps alone were used to determine the location and organization of sensory fields because the cortical architecture was difficult to identify after the numerous electrode penetrations, and the architecture was often irregular (see below). In the one case in which anatomical tracers were placed in the neocortex, the injection site locations and spread were reconstructed from serial sections and transposed onto a digital image of the cortex. From the series of sections mounted for fluorescent microscopy, the thalamic cell bodies labeled with FE, DY + NY, and FR were plotted in $x-y$ coordinates using a fluorescent microscope equipped with a digitizer attached to a personal computer. Using blood vessels and other tissue landmarks, the locations of plotted cell bodies were determined by transposing the thalamic nuclear boundaries from tissue stained for Nissl and CO.

To determine the relative contribution from each major sensory projection nucleus in the thalamus to a circumscribed location of the cortex, back-labeled cells in the thalamus were counted, and percentages were computed for each of the tracers used. All of the labeled cells in the thalamus for each tracer were counted in nine alternate sections (one section every $150 \mu \mathrm{m}$ ) where all labeled cells were plotted, and nuclear boundaries were determined. For each tracer, the total number of cells for the series within the dorsal division of the lateral geniculate nucleus (LGd), the medial geniculate nucleus (MG), and the ventral posterior nucleus (VP) was determined, and the percentage of the total number of labeled cells was computed (see Table 1).

To determine whether the changes in the size of the diencephalon ipsilateral to the lesion were significantly different from normal, volumetric measurements of the diencephalon in three normal animals and three of the animals that underwent cortical removals were made. Two males and one female were used in each group. Weights ranged from 80 to 130 gm. Volume estimates were determined based on samples from every third section (stained for Nissl). To make these volumetric measurements, it was necessary to appoint equal anterior and posterior levels of the diencephalon across cases. The anterior level was assigned as the level at which the habenula began. The posterior level was assigned as the level at which the superior colliculus (SC) and the MG were both present in the same section. The area of the ipsilateral diencephalon was measured using the software NIH image 1.61. Volume estimates were calculated by summing the product of the surface area $(A)$ and the distance $(D)$ between sampled sections, across all sections sampled. This is expressed as

$$
V=\sum_{\mathrm{i}=1}^{\mathrm{n}}\left(A_{\mathrm{i}} \times D\right) .
$$

$n=$ the total number of sections sampled. After all volumes were determined, a one-way ANOVA was performed to assess group differences.

\section{RESULTS}

Reductions in the size of the neuroepithelial sheet before the arrival of thalamic afferents had five effects on the adult neocortex and subcortical structures. First, visual and auditory fields formed on the remaining cortical sheet in a position not normally occupied by these fields. Second, the size of some of the cortical fields on the remaining cortical sheet was reduced. Third, the thalamocortical afferents retained their normal relative spatial relationships with the diminished cortex. Fourth, the laminar architecture of the cortex, as defined using Nissl, CO, and myelin stains 


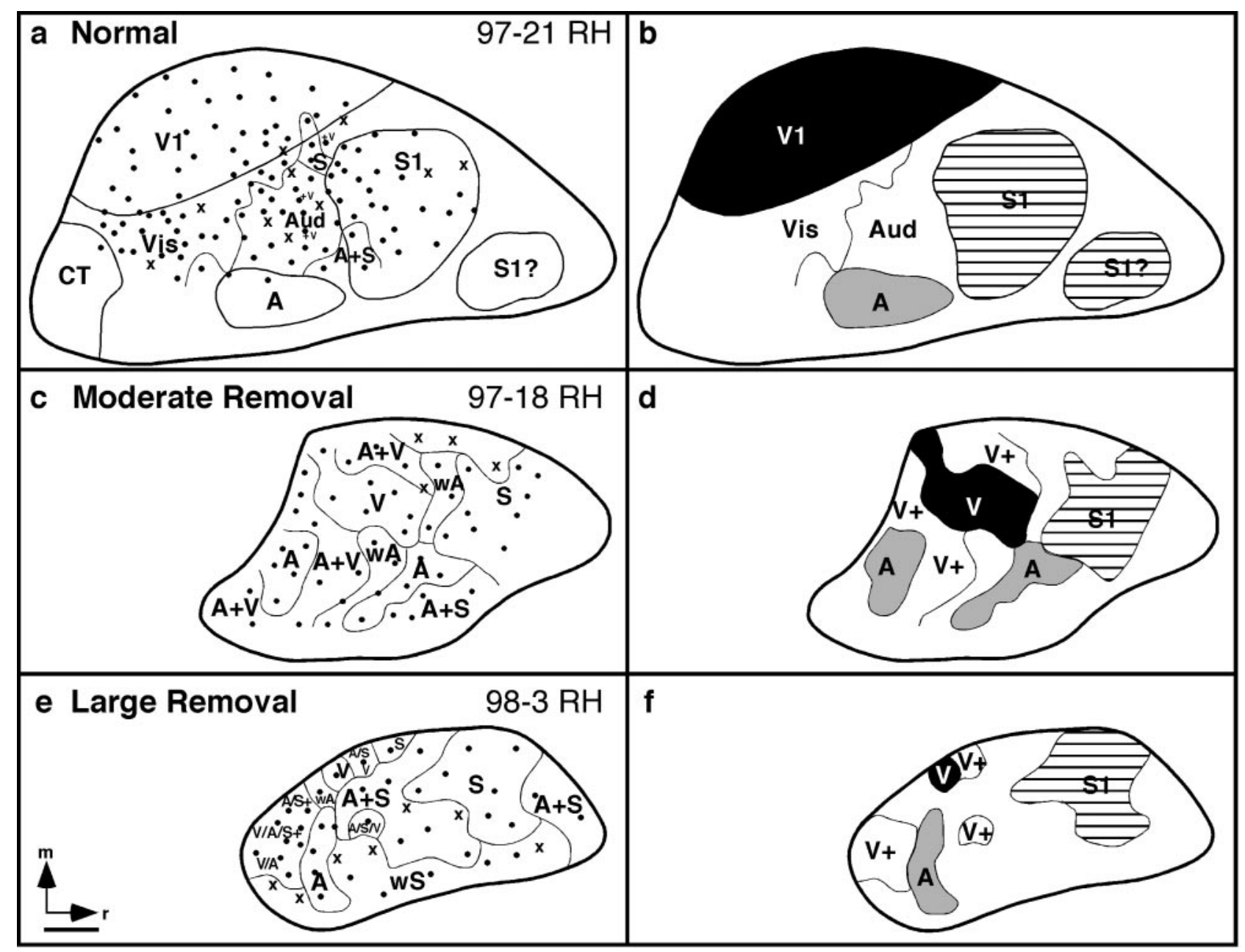

Figure 3. Electrophysiological recording results from a right cortical hemisphere of a normal adult $(a, b)$ and two right cortical hemispheres of adults that underwent removal of a portion of the cortical neuroepithelium at P4 (c-f). The illustrations to the left depict recording sites (black dots); thin lines represent physiological boundaries that enclose regions of the cortex in which neurons responded to the same sensory modality. The illustrations at the right denote the primary sensory fields, including the primary visual, primary somatosensory, and presumptive primary auditory field $(V 1, S 1, A)$ in the normal animal $(b)$, and the pure visual, somatosensory, and auditory fields $(V, S 1$, and $A)$ in the animals with moderate $(d)$ and large $(f)$ cortical removals. In the normal animal, thick dark lines $(a, b)$ denote architectonic boundaries. Despite the large removals of the developing neocortex, the pattern of general rostrocaudal and mediolateral organization of cortical fields, although compressed, was relatively normal. A noteworthy change in the neocortex was that as the extent of the reduction increased, the relative amount of multimodal cortex increased. Scale bar, $1 \mathrm{~mm}$. $V$ or $V i s$, Visual; $A$ or $A u d$, auditory; $S$, somatosensory; $A+S$ or $A / S$, auditory and somatosensory; $A+V$ or $V / A$, auditory and visual; $V / A / S$, visual, auditory, and somatosensory; $w A$, weak auditory; $w S$, weak somatosensory; $V+$, visual + other sensory input; $x$, no response; $C T$, caudal temporal field; $m$, medial; $r$, rostral.

appeared irregular in most of the regions of cortex. Fifth, the entire dorsal thalamus and superior colliculus on the side of the brain in which the cortex was removed were reduced.

\section{Electrophysiological recording}

After the removal of one-third to three-fourths of the neuroepithelial sheet, electrophysiological recording techniques were used to determine the gross functional organization of the remaining neocortex in the adult (Figs. 2, 3). In normal marsupials, the primary visual field (V1) occupies approximately one-third of the cortex and is located at the caudomedial pole (Kahn et al., 1999; Rosa et al., 1999). The primary somatosensory field (S1) is located rostral to $\mathrm{V} 1$ and is somewhat smaller in size than V1 (Huffman et al., 1999). Although the primary auditory field (A1) has not been described fully in Monodelphis, a densely myelinated region of cortex in which neurons respond only to auditory stimulation has been identified in the location of A1 in other marsupials (Gates and Aitkin, 1982; Aitkin et al., 1986). We term the field A because of uncertainties in homology with A1 in other mammals. Cortex just rostral and lateral to V1 (termed here V) is dominated by visual inputs, whereas cortex medial to $\mathrm{A}$ and rostral to $\mathrm{V}$ is dominated by auditory inputs (A), although a few sites contained neurons that responded to visual stimulation. Cortex lateral to S1 contains neurons responsive to both somatosensory and auditory stimulation (Fig. $3 a, b$ ).

In the cases in which the cortical neuroepithelium was reduced by approximately one-third to one-half [97-22, data not shown; 97-18, moderate removal (Fig. $3 c, d$ )], some aspects of organization appeared similar to that of normally organized brains of Monodelphis, and other aspects were different. For example, we were able to identify three major sensory regions that exclusively represented visual, auditory, or somatosensory inputs, which we term $\mathrm{V}, \mathrm{A}$, and $\mathrm{S} 1$, respectively. Because we did not obtain a retinotopic map of visual cortex, we cannot say that this region is $\mathrm{V} 1$, like that described in normal animals. However, despite the 

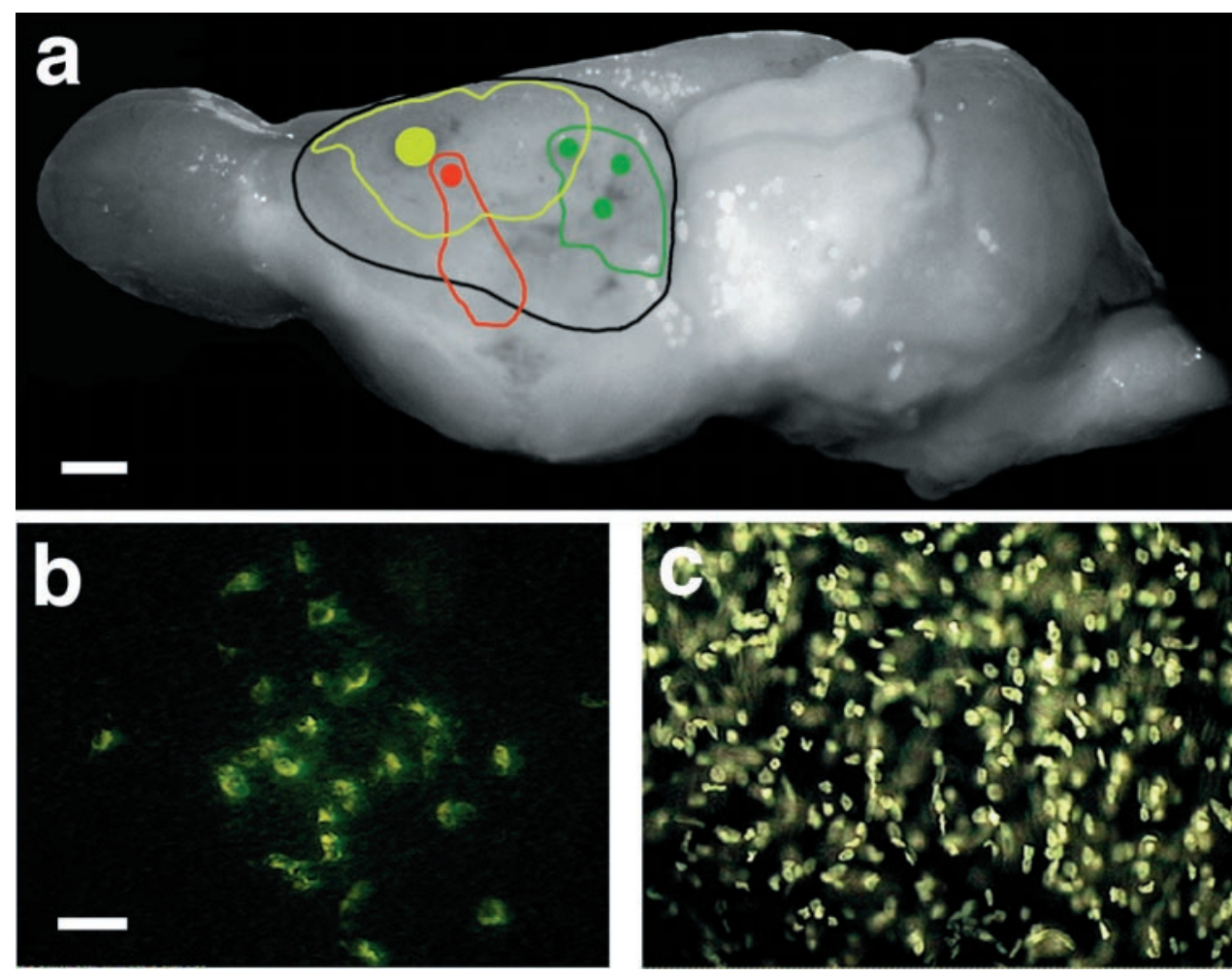

Figure 4. a, Digital image of a brain (case 98-31) that underwent removal of the cortical neuroepithelium at $\mathrm{P} 4$, and a superimposition, using the software Adobe Photoshop 4.0, of the center and spread of the injection sites on the left cortical hemisphere. Scale bar, $1 \mathrm{~mm}$. The injections included DY + NY (yellow) into a rostral portion of cortex, FR (red) into a middle portion of cortex, and three injections of FE (green) into the caudal pole of the cortex. $b$, Digital image of retrogradely labeled cells in the dorsal division of the LGN resulting from an injection of FE into the caudal pole of the remaining cortex, in the expected location of visual cortex. Scale bar for $b, c, 50 \mu \mathrm{m}$. $c$, Digital image of retrogradely labeled cells in the VP resulting from an injection of DY + NY in the presumptive somatosensory/multimodal cortex. fact that all or most of what would be visual cortex was removed, a region of cortex containing neurons that responded exclusively to visual stimulation was located in the caudomedial portion of the remaining cortex. Thus, the relative position of fields on the remaining cortical sheet was similar to normal animals. Unlike in normal animals, there appeared to be more cortex that was dominated by mixed inputs such as auditory and visual. Also, a second zone of pure auditory inputs was identified caudally, in a location that was separate from A described in normal animals. Finally, the relative size of $\mathrm{V}$ was substantially reduced, whereas the relative size of S1 appeared only slightly smaller than in normal animals. The relative amount of cortical space occupied by pure auditory inputs appeared larger.

In cases in which substantially more cortex was removed [e.g., approximately three-fourths of the cortical neuroepithelial sheet; 98-4, data not shown, and 98-3 (Fig. 3e, f, Large Removal)], including all of the putative visual neuroepithelium and much of the putative auditory neuroepithelium, we still identified regions of the cortex that were dominated by visual, auditory, or somatosensory inputs. However, the region in which neurons responded only to visual stimulation, and no other modality, was identified only at a single recording site. Although the presence of a purely visual cortical field is questionable, the caudal portion of the remaining cortex did contain neurons that responded to visual stimulation in addition to somatosensory and auditory stimulation (Fig. 3e,f). This "visual cortex" is located in a rostral position in comparison to normals. Cortex rostral to this contained neurons that responded to auditory stimulation alone, auditory and somatosensory stimulation, or somatosensory stimulation alone. As in the case of the moderate removal, the cortex that resided between the major sensory domains was multimodal.

\section{Thalamocortical connections}

Injections of anatomical tracers into rostral, middle, and caudal locations in the cortex in which approximately one-half of the neuroepithelium was removed demonstrated that thalamocortical afferents maintain a normal relative pattern in terms of their gross rostrocaudal organization (Fig. 4). Specific patterns of thalamic afferents could not be ascertained because injections were not placed under electrophysiological guidance. We purposely injected large amounts of tracer to ensure success in backlabeling cells in the thalamus and to allow us to examine large scale thalamocortical topographic relationships. An injection of DY + $\mathrm{NY}$ in the far rostral pole of the neocortex (Fig. $4 a$ ) resulted in a large number $(72 \%)$ of retrogradely labeled cells in the VP of the thalamus (Figs. 4c, 5; Table 1). VP is one of the major thalamic nuclei associated with processing somatic inputs. Twenty-one percent of the retrogradely labeled DY + NY cells were also observed just dorsal to VP (in the posterior nucleus), and only $7 \%$ were identified in the lateral geniculate nucleus (Fig. 5, LGN; Table 1). This injection was in the expected location of S1 as electrophysiological studies in other cases demonstrate, but was very large and likely to have spread into portions of visual cortex as well. No labeled cell bodies were identified in the MG from this injection.

The injection of FR into a location just caudal to the DY + NY injection resulted in $63 \%$ of the labeled cells in VP, $14 \%$ in MG, and $6 \%$ in LGd (Table 1). This injection was in the expected location of somatosensory cortex, although it spread into the expected locations of auditory and multimodal cortex. The three small injections of FE in the caudal pole of cortex were placed in the expected location of visual cortex, or multimodal cortex, which includes neurons responsive to visual stimulation. Fortyeight percent of the retrogradely labeled cell bodies were found in the LGd (Figs. 4b, 5), $40 \%$ were in VP, and $4 \%$ were in MG. The injections of bi-directional tracers FE and FR also labeled axons in the cerebral peduncle. The remaining labeled neurons in the thalamus that were not found in the major projection nuclei were found dorsal to the posterior portion of $\mathrm{VP}$ (in the posterior 


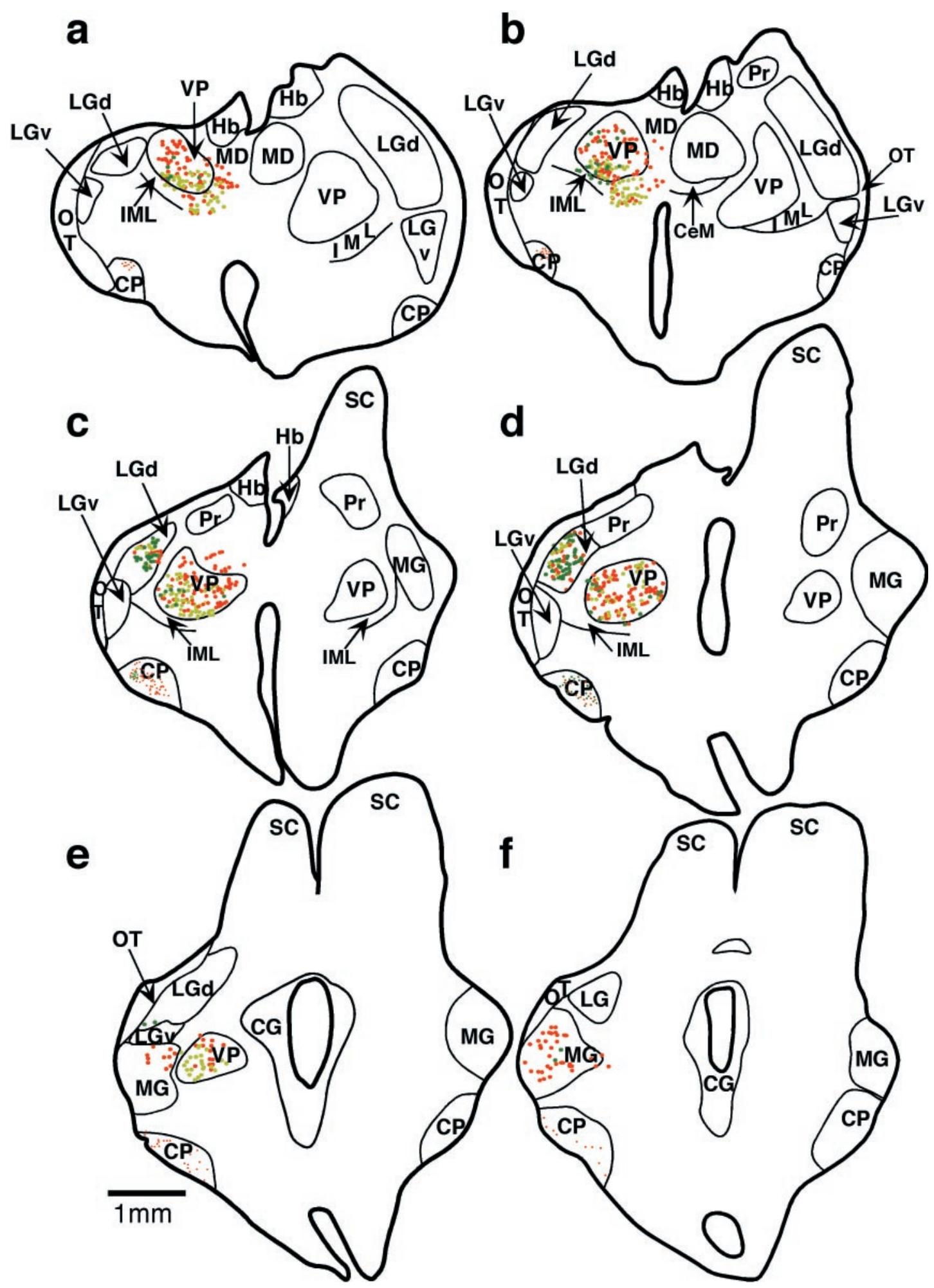

Figure 5. A series of sections from anterior to posterior through the thalamus of case 98-31 $(a-f)$. Each dot represents a retrogradely labeled cell body from a cortical injection in the left hemisphere. Yellow dots are cells labeled with DY + NY, red dots are cells labeled with FR, and dark green dots are cells labeled with FE. Thin lines represent nuclear boundaries determined by architectonic analyses of alternate, neighboring sections stained for Nissl or CO. Throughout the thalamus, most of the DY + NY-labeled cells were located in VP, although some of these cells were also found in the LGd. Most FR cells were observed in the VP, although some were seen in the MG and a few were observed in LGd. Labeled cells resulting from the most caudal set of injections in the cortex (FE) were mostly found in the LGd, demonstrating that although the entire occipital lobe was absent in this case, the LGd maintained substantial projections to the caudal portion of the remaining cortex, where, in other cases, visually responsive neurons were found. Portions of axons (small dots) labeled with FR and FE were found in the cerebral peduncle $(\mathrm{CP})$. Some of the thalamic boundaries are taken from Turlejski et al. (1994). Scale bar, $1 \mathrm{~mm}$. Hb. Habenula; $M D$, mediodorsal nucleus; $L G v$, ventral division of the lateral geniculate nucleus; $O T$, optic tract; $I M L$, internal medullary lamina; $C e M$, central medial nucleus; $P r$, pretectum; $S C$, superior colliculus; $C G$, central gray. Dorsal is to the top, and lateral is to the left and right of each section. 


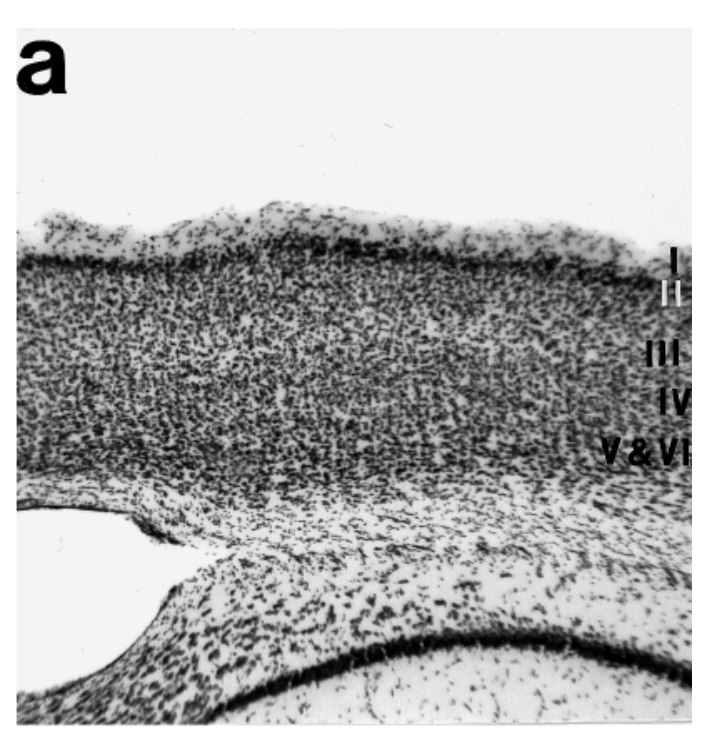

\section{b}
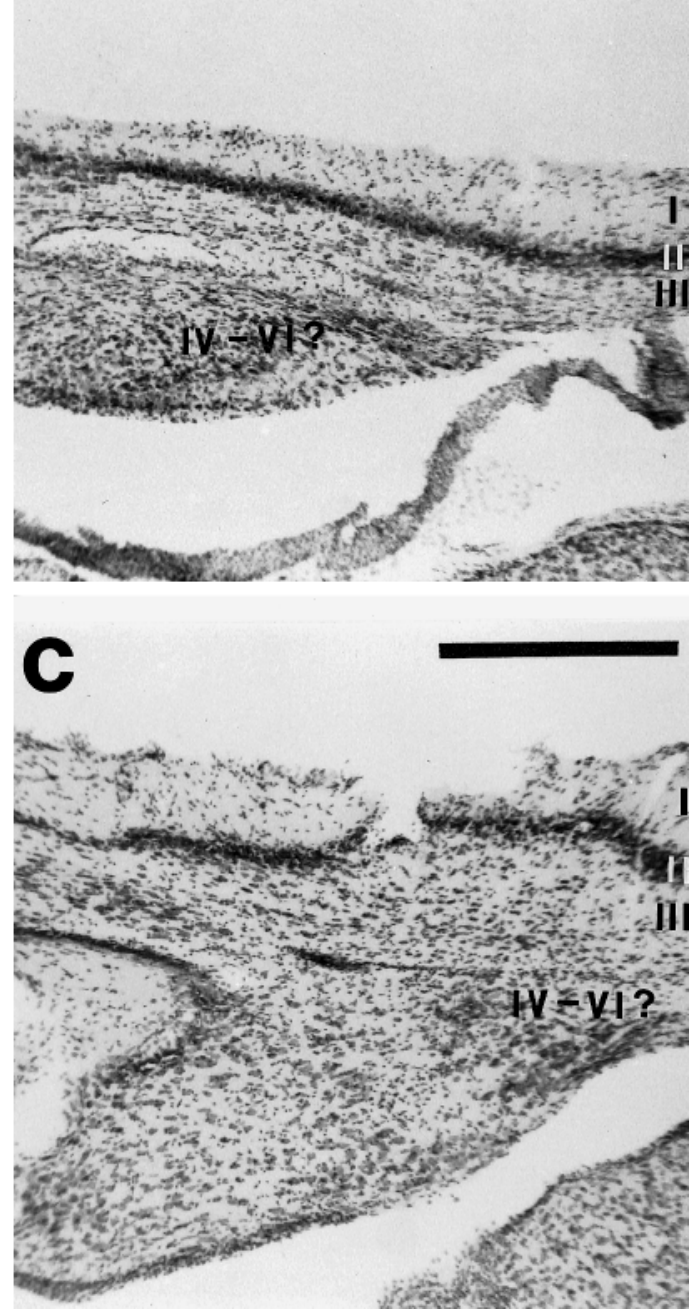

Figure 6. $a$, Photomicrograph of normal adult neocortex that has been cut coronally and stained for Nissl. The photomicrographs in $b$ and $c$ are from an adult neocortex where a moderate cortical neuroepithelial removal was made at P4. Cortex in this region appears normal in terms of laminar organization $(b)$, although this was not the case for the entire
Table 1. Percentage of labeled cells in thalamic nuclei from three tracers

\begin{tabular}{lcrr} 
& DY + NY & FR & FE \\
\hline$\%$ of cells in VP & 72 & 63 & 40 \\
$\%$ of cells in MG & 0 & 14 & 4 \\
$\%$ of cells in LGd & 7 & 6 & 48 \\
$\%$ of cells in other nuclei & 21 & 17 & 8 \\
\hline
\end{tabular}

The percentages of labeled cells in the three major thalamic projection nuclei were calculated for three tracer injections into cortices of animals in which approximately one-third to one-half of the neocortex was removed at P4. Diamidino yellow + nuclear yellow (DY + NY) was injected into the presumptive somatosensory cortex, but the injection site was large and spread into visual cortex as well. Most of the labeled cells were found in the ventral posterior nucleus of the thalamus (VP). An injection of flouroruby (FR) was placed just caudal to DY + NY and spread into the presumptive auditory cortex and multimodal cortex. Most of the labeled cells were in VP. Labeled cells were also found in the medial geniculate nucleus (MG) and the dorsal division of the lateral geniculate nucleus (LGd). Three small injections of flouroemerald (FE) were placed at the caudal pole of the remaining cortex. Most labeled cells were found in LGd, almost as many were found in VP, and a few cells were found in MG.

nucleus) and ventral to the anterior aspect of VP (in the ventral lateral nucleus).

\section{Cortical architecture}

Our laboratory routinely combines architectonic analysis with physiological recording results (Huffman et al., 1999). In the normal Monodelphis, S1, A, and V1 correspond to myelin dense regions with a granular layer IV (Huffman et al., 1999; Kahn et al., 1999). In the animals that received cortical ablations very early in development, these types of architectonic distinctions were not possible. In some regions, the cortex was thinner than in normal animals (Fig. 6). Nissl stains allowed us to identify some of the superficial cortical layers, although field distinctions were not possible (Fig. 6). In other regions of cortex, particularly in the caudalmost region, the cortex was thicker than in normal animals (Fig. 6), and although different layers could be recognized, the overall appearance of the cortex was irregular (Fig. 6).

\section{Subcortical structures}

Examination of tissue stained for Nissl and $\mathrm{CO}$ revealed that nuclei in the thalamus, ipsilateral to the cortical removal, appeared normal in both their relative location in the dorsal thalamus and their architectonic appearance (Figs. 7, 8). Thus, VP stained darkly for $\mathrm{CO}$ and contained densely packed cells. The LGd was a darkly CO-stained, cell-dense nucleus in the lateral and dorsal aspect of the thalamus [see Turlejski et al. (1994) and Kahn et al. (1998) for normal descriptions of thalamic nuclei in Monodelphis]. The MG was in a caudal location, just ventral to the SC and LGd. Other nuclei such as the mediodorsal nucleus $(M D)$, the pretectal nucleus $(P r)$, the central medial nucleus $(C e M)$, and the ventral division of the lateral geniculate nucleus $(L G v)$ also appeared normal in cell staining and $\mathrm{CO}$ densities (Figs. 7, 8).

The most notable difference in the dorsal thalamus ipsilateral to the cortical lesion was the overall reduction in its size. In the cases in which larger portions of the cortex were removed, the thalamic reduction was more dramatic (Fig. $7 c-f$ ). Volumetric measurements for three cases in which the cortex was removed at

$\leftarrow$

extent of the reduced cortex. In some portions of the cortex, particularly the region toward the caudal end of cortex $(c)$, the laminar organization of the cortex was more disrupted. Dorsal is up; lateral is to the right. Scale bar, $1 \mathrm{~mm}$. 
2 Normal

98-7
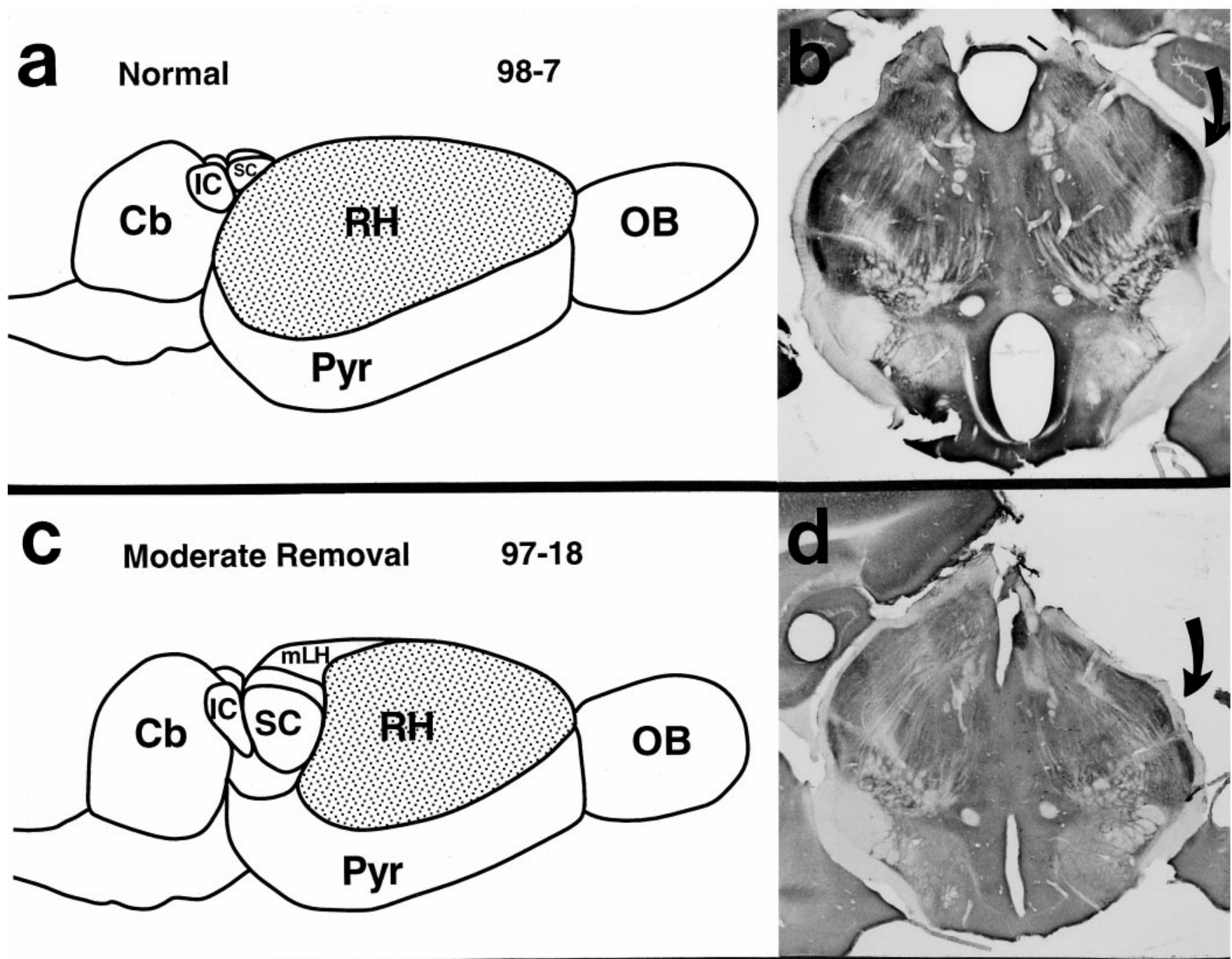

e

Large Removal

98-3
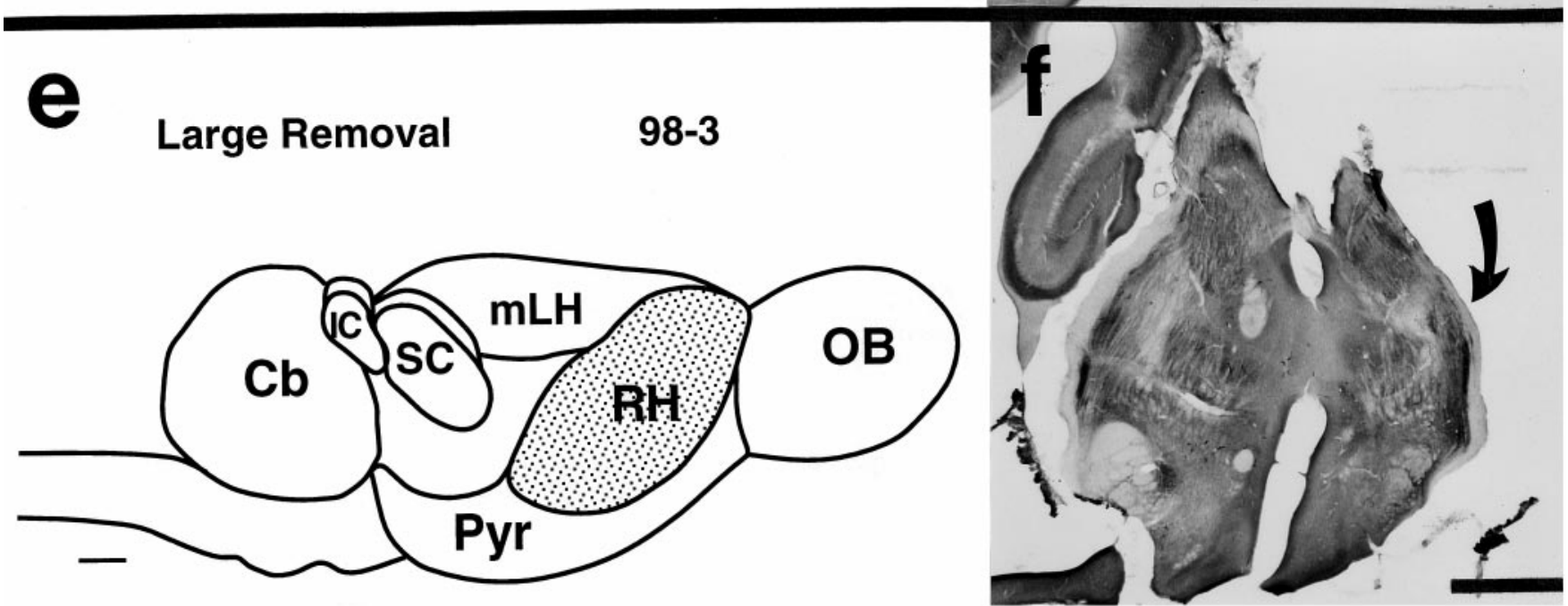

Figure 7. Illustrations of a dorsolateral view of the brain in the normal animal $(a)$ and of one that has undergone a moderate $(c)$ and a large $(e)$ cortical removal. Photomicrographs of coronally cut CO-stained sections from the corresponding thalamus $(b, d, f)$. Although the overall size of the thalamus has decreased, nuclear boundaries were still discrete. The LGd (arrows) can be seen in all cases. Scale bar, $1 \mathrm{~mm}$. $C b$, Cerebellum; $S C$, superior colliculus; $I C$, inferior colliculus; $R H$, right hemisphere; $P y r$, pyriform cortex; $O B$, olfactory bulb; $m L H$, medial wall of the left hemisphere. 
Table 2. Volumes of diencephalon in normal and cortex-reduced animals

\begin{tabular}{|l|c|c|l|l|c|}
\hline \multicolumn{3}{|c|}{ Normal } & \multicolumn{3}{c|}{ Reduced cortex } \\
\hline Case \# & sex & volume $\left(\mathrm{mm}^{3}\right)$ & Case \# & sex & volume $\left(\mathrm{mm}^{3}\right)$ \\
\hline $98-7$ & male & 19.9 & $97-18$ & female & 14.4 \\
\hline $98-35$ & male & 21.8 & $98-3$ & male & 11.7 \\
\hline $99-11$ & female & 18.8 & $98-4$ & male & 10.8 \\
\hline Mean & 20.2 & Mean & 12.3 \\
\hline St. Dev. & 1.5 & St. Dev. & 1.9 \\
\hline F(1,4)=31.9, $P=0.005$ &
\end{tabular}

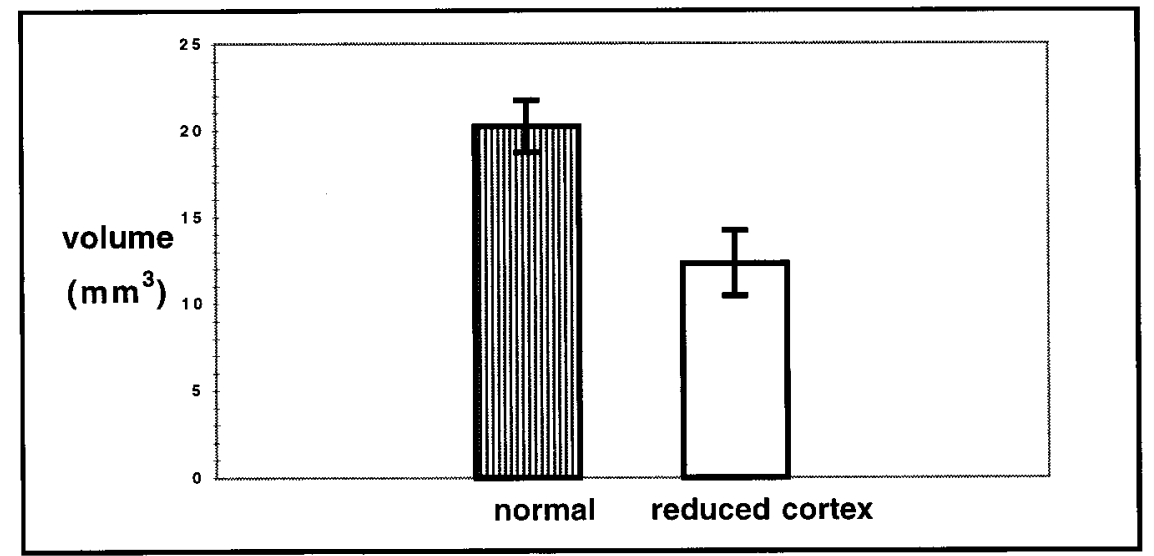

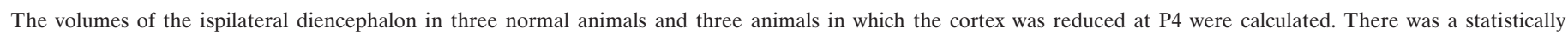
significant difference in the size of the diencephalon between normal and cortex-removed animals. The bottom bar graph illustrates this difference.

P4 and three normal cases indicate that the size of the ipsilateral diencephalon in manipulated animals $\left(M=12.3 \mathrm{~mm}^{3}\right)$ was significantly smaller than in normal animals $\left(M=20.2 \mathrm{~mm}^{3}, F_{(1,4)}=\right.$ 31.9, $p=0.005$; Table 2). The nuclear boundaries remained distinct, the cell size and density appeared normal, and normal nuclear relationships were preserved (Figs. $7 d, f, 8)$.

A similar reduction in size was noted in the SC on the side of the lesion (Fig. 9). The laminar boundaries were distinct, and the cellular densities appeared to be similar in normal and lesioned animals and between normal and lesioned sides of the same brain. Thus, layers II and IV contained a number of tightly packed cells, layer I was cell sparse, and layers III, V, and VI contained moderately packed cells. As in the thalamus, the size of the reduction appeared to be related to the size of the lesion in the cortex.

\section{DISCUSSION}

Observations of cortical organization in various extant adult mammals indicate that cortical field position can shift dramatically in different lineages with changes in peripheral morphology and with changes in the size of the cortical sheet (Fig. 10). These observations have led us to propose that cortex is initially a homogeneous sheet and that patterns of connections, rather than some unique attribute of a particular piece of cortex, are homologous across species (Krubitzer et al., 1993; Krubitzer, 1995). Over time in different lineages these patterns of connections may redistribute with the expansion of the cortical sheet (Kaas, 1989, 1993; Krubitzer et al., 1993; Krubitzer, 1995, 1999) and develop and become refined during the life of the individual (Merzenich et al., 1987, 1991; Kaas, 1991; Huffman et al., 1999). On the basis of this proposal, we reasoned that if we reduced the size of the cortical sheet before thalamic afferents arrived or other connections had formed, we would get a new distribution of afferents. In contrast, if the changes to mammalian neocortex observed in extant animals are caused by geographic displacement of tissue that was already specified, then removing the portion of the developing cortex "destined" to be V1 and all of extrastriate cortex should result in the absence of visual cortex in the adult. This would leave the extent of other sensory fields unaffected. In a previous study of early cortical lesions in newborn rats (Cunningham et al., 1987), no substantial rearrangement occurred in thalamocortical matching. The lateral geniculate nucleus degenerated, whereas the other nuclei maintained their original size. However, the major difference between our study and the previous study is that in the former study the neocortex was removed after the thalamic fibers had entered the appropriate cortical fields.

\section{Cortical fields can form in a new location on portions of the cortical sheet that would normally be occupied by a different sensory modality}

Our findings that all sensory inputs are represented on a cortex that has been substantially reduced in size, and therefore have arrived in a new location compared to that which they normally would occupy, suggest that the cells of the early neural sheet are capable of remarkable plasticity. However, the relative rostrocaudal and mediolateral relationships of cortical fields and thalamic afferents appear to be highly conserved. What are the mechanisms that determine these relationships?

Currently, there are several different views on how cortical 


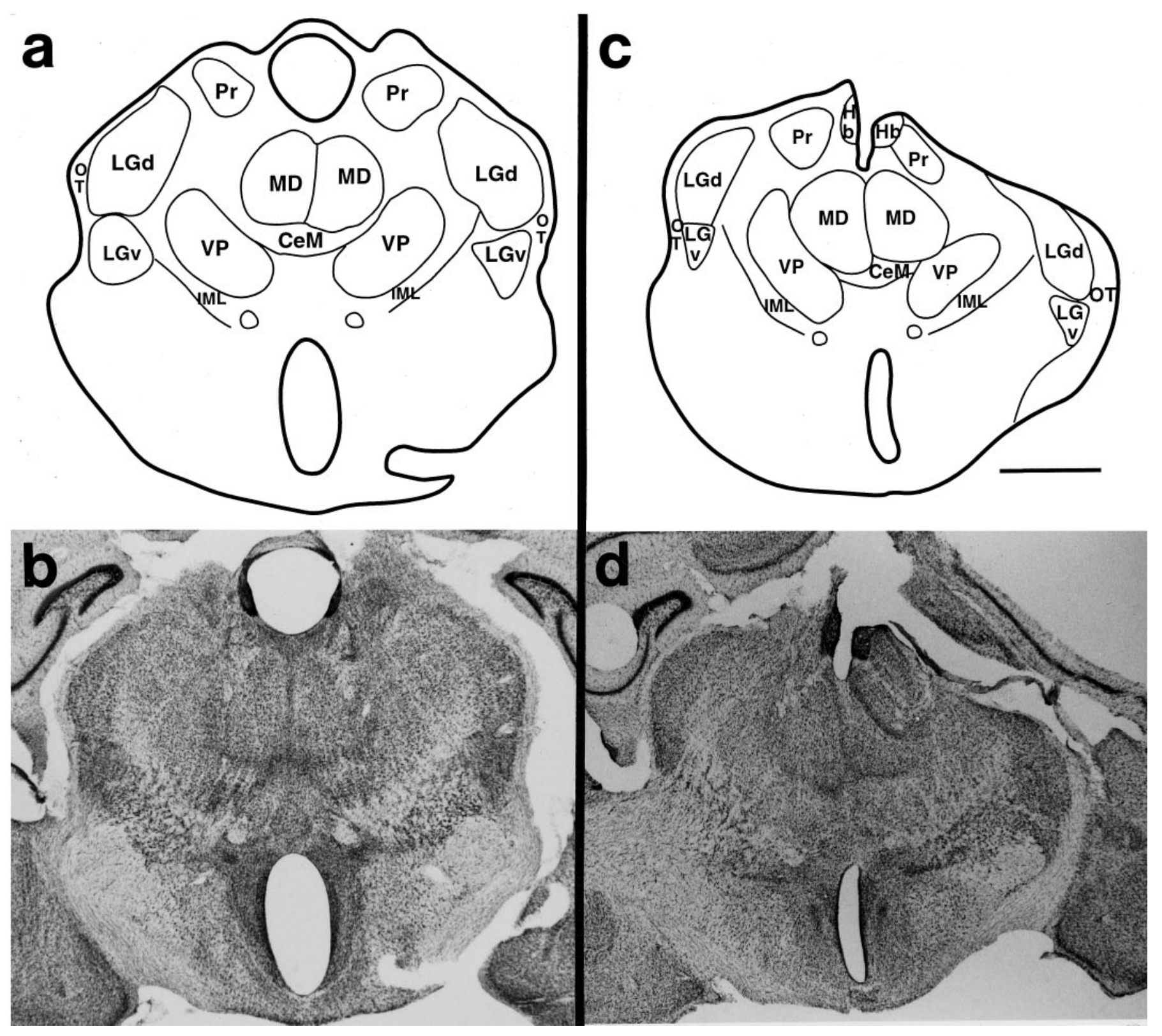

Figure 8. $\quad a, c$, Reconstructions of the Nissl sections photographed in $b$ and $d$. These sections of the thalamus are from normal animals ( $a$ ) and those with a moderate cortical removal $(c)$. Thin lines mark nuclear boundaries determined by architectonic analyses. The corresponding photomicrographs $(b, d)$ demonstrate that although the thalamus has been reduced on the side of the lesion, nuclear architecture is still distinct. Scale bar, $1 \mathrm{~mm}$.

fields develop. One proposal is that a protomap exists within the ventricular zone, and cortical field organization is specified very early in development (Rakic, 1988; Barbe and Levitt, 1995; Levitt et al., 1997). In this scenario, there is something inherent in a particular piece of the cortical neuroepithelium that directs it to produce a particular field. Support for this theory comes from studies in monkeys and rats in which differential laminar histogenesis is observed for different regions of the ventricular zone destined to become particular cortical fields (Dehay et al., 1993; Polleux et al., 1997a,b). Further support comes from studies that demonstrate differential molecular expression patterns in different domains during corticogenesis (Cohen-Tannoudji et al., 1994; for review, see Rakic, 1995b; Levitt et al., 1997). Finally, Gbx-2deficient mice in which the thalamus fails to innervate the developing cortex still possess region-specific gene expression in the neocortex at P0 (Miyashita-Lin et al., 1999). Although sharp boundaries of gene expression do exist in the absence of thalamic input [boundary ii in Miyashita-Lin et al. (1999)], it is unclear how they relate to explicitly defined cortical field boundaries. Indeed, the authors state in a previous study that examined the patterns of expression of $I d-2$ (boundary i) that ". . . Id-2 expression in layer 5 ends abruptly, clearly demonstrating another intracortical rostrocaudal boundary. ... The position of this boundary may be the transition between frontal (motor) and parietal (sensory) cortical areas ..." as defined architectonically in adult rats by Zilles and Wree (1995) [also see Bulfone et al. (1995) and Suzuki et al. (1997)]. It would be useful to examine the exact relationship of these patterns to cortical fields and to determine whether these patterns shift in our experimental animals.

A less stringent version of the protomap hypothesis is that 

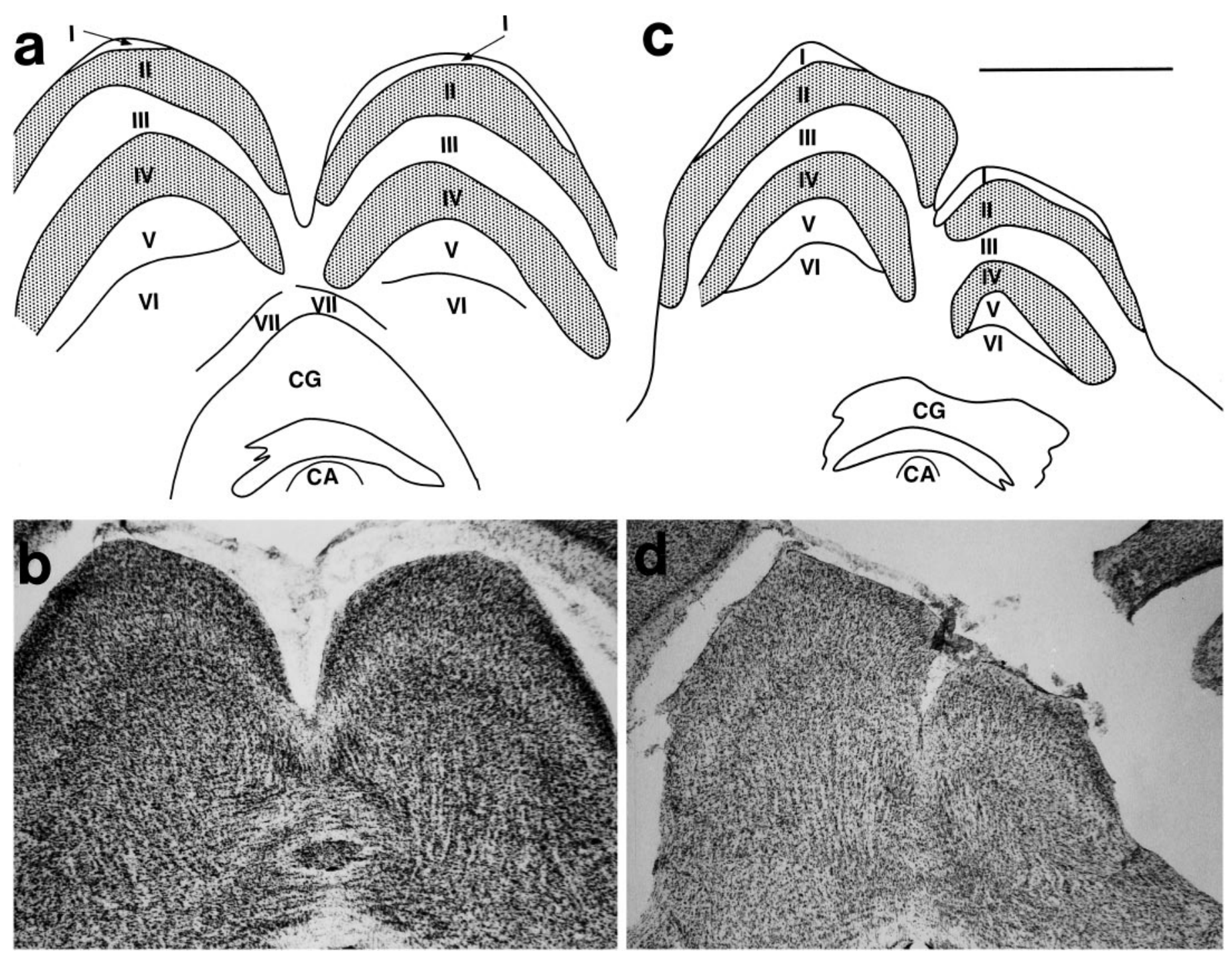

Figure 9. Illustrations of reconstructed Nissl sections $(a, c)$ through the SC in the normal animal $(a)$ and an animal that had undergone a moderate cortical removal at P4 (c). Thin lines mark boundaries between layers of the SC and of the CG. Stipple indicates cell-dense layers II and IV. $b$, $d$, Photomicrographs of those sections in the normal $(b)$ and moderate removal $(d)$ animals. Although the SC in the moderate cortical removal animal is reduced in size, its laminar pattern appears to be maintained. $C A$, Cerebral aqueduct. Scale bar, $1 \mathrm{~mm}$. Conventions are as in previous Figures.

there is differential gene expression in the developing cortex that reflects subsequent specialization (Levitt et al., 1997) and sets up the anteroposterior and mediolateral axis of the cortex, which in turn allows thalamocortical relationships to be maintained. For instance, differential expression of regulatory homeobox genes such as Emx2 and Pax6 sets up a general rostrocaudal molecular gradient that may control the ordered growth of thalamic afferents (Guilisano et al., 1996; for review, see Chenn et al., 1997).

Pioneering studies by Sperry suggested that topographic relationships in the developing nervous system are initially instigated by chemoaffinities between the incoming afferents and the target tissue (Sperry, 1963). A modern synthesis of Sperry's initial formulation is that chemoaffinities are not specific but that molecular gradients in different structures set up a directional axis and specify regional identity (O'Leary et al., 1994; Rubenstein and Beachy, 1998) and promote ordered afferent ingrowth (Richards et al., 1997; Frisén et al., 1998; Mann et al., 1998; for review, see O'Leary et al., 1999). Although results from the present study do not directly address this issue, they are consistent with the view that these gradients may provide relative positional cues or may be capable of rapidly changing their patterns if the environment in which they reside has been altered dramatically.

Although the present results as well as comparative studies of cortical organization in different mammals (Fig. 10) demonstrate that thalamocortical relationships and relative geographic location of cortical fields appear to be highly conserved, a number of important questions regarding area specification still remain unanswered. For example, what promotes differential gene expression and consequent molecular gradients? It has been proposed that the microenvironment in which the developing cells find themselves plays a large role in this process (Ferri and Levitt, 1995; Lillien, 1998), but the boundaries of the environment still need to be defined. It may be useful to examine the role of the structures that border the cerebral cortex, such as the superior colliculus/cerebellum (caudal), the olfactory bulb (rostral), and the pyriform cortex (lateral), in defining its boundaries.

A second view of cortical field differentiation holds that cortical fields are specified late in development and that thalamocortical 


\section{a. Platypus}

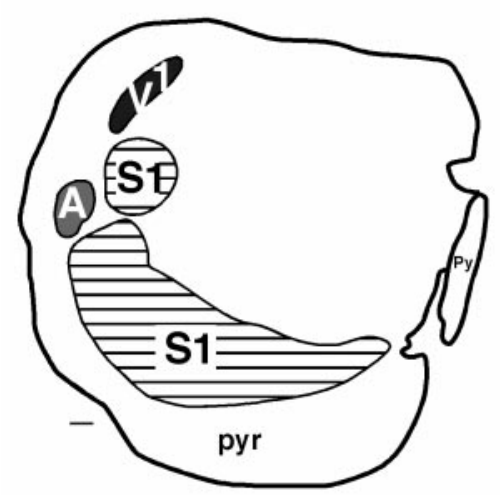

b. Tenrec

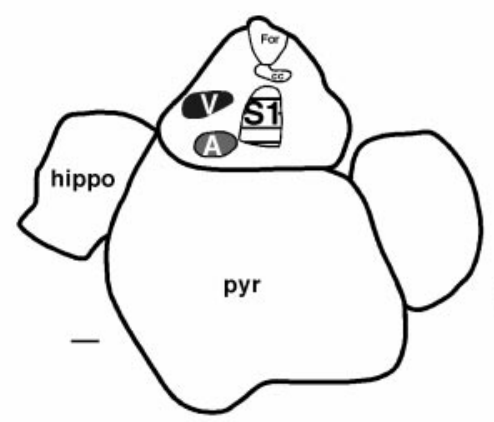

\section{Dunnart}

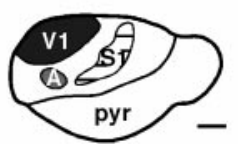

d. Squirrel

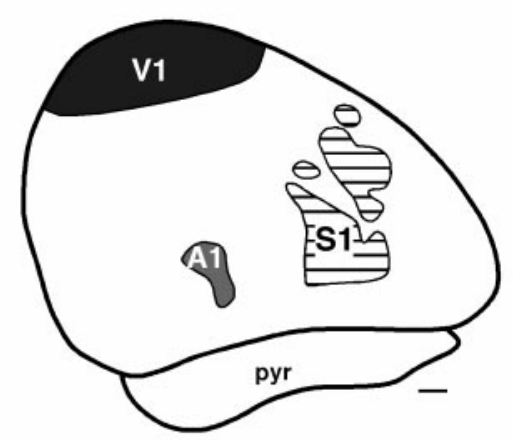

e. Marmoset

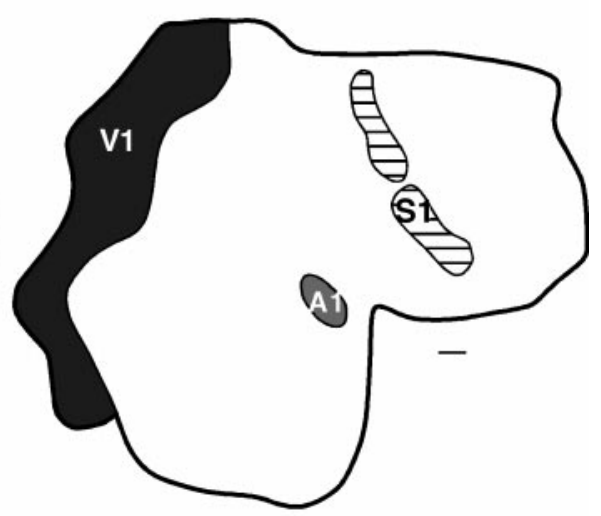

including $S 1, A$, and $V 1$ in various mammals. Although common areas can be identified across species, the geographic placement of these fields has shifted dramatically in different lineages with changes in cortical sheet size and peripheral specializations. With the expansion of the cortical sheet, cortical fields get larger, but this enlargement is not linear. Scale bar, $1 \mathrm{~mm}$. Conventions are as in previous Figures.

connections play an important role in assigning cortical fields (O’Leary, 1989; Killackey, 1990; Roe et al., 1990; Molnár and Blakemore, 1991; Windrem and Finlay, 1991; Killackey et al., 1994). This proposal is supported by studies in which the developing neocortex from one region is transplanted into another region and then takes on the properties of the host (Schlaggar and O'Leary, 1991). Other studies that support this idea demonstrate that in vitro thalamocortical axons will grow toward any portion of the cortex, regardless of whether it is a region of cortex that they would normally innervate (Molnár and Blakemore, 1991, 1999). Finally, studies of cell lineage and dispersion demonstrate that clonally related neurons can disperse over a wide region of cortex and span several architectonic fields (Walsh and Cepko, 1992, 1993).

Our findings demonstrate the ability of early thalamocortical projections to innervate a novel location of the neuroepithelium on the reduced cortical sheet. These results complement previous studies in hamsters, in which visual inputs were rewired to ultimately innervate somatosensory cortex (Frost and Metin, 1985), and in ferrets, in which visual inputs were rerouted into auditory cortex (Roe et al., 1990, 1992; Pallas et al., 1990; Pallas and Sur, 1993). In the latter study, the "auditory" cortex was dominated by visual inputs but had connections that were consistent with auditory cortex (Pallas et al., 1990; Pallas and Sur, 1993). However, the topography of the maps that formed was like those in visual cortex. The authors suggest that cortical area specification occurs late in development, and a cortical area can be induced to support different types of maps (Roe et al., 1990, 1992).

Taken together, the consistencies across data sets indicate that the early embryonic cortical neuroepithelium is plastic, and its specification depends on the spatially and temporally regulated environmental signals that can alter the potential of its cells (Lillien, 1998). Thus, the cortex can be reassigned in development. The way in which the reassignment occurs is constrained anteroposteriorly and mediolaterally, perhaps by highly conserved but not immutable patterns of graded gene expression in these two axes. Another possibility, not mutually exclusive from the former, is that the overall geometry of the neocortex may reflect the spatial relationship between thalamic nuclei, which is highly conserved across mammals.

\section{Reduction in the size of the cortical neuroepithelium results in a reduction in the dorsal thalamus and superior colliculus}

Our observation of a decrease in size in the dorsal thalamus may be explained in two ways. One possibility is that there is a retrograde effect on the developing thalamic afferents resulting from a decrease in the size of the target. Regulation of cell death 
by the target (Cowan et al., 1984; for review, see Oppenheim, 1999) and target-induced changes in cellular morphology of developing afferents (Erzurumlu et al., 1994; Erzurumlu and Jhaveri, 1995; Ling et al., 1997) have been well established. The second possibility is that corticothalamic afferents from the target are reduced, and this reduction promotes thalamic cell death. The two possibilities are not exclusive. Although it is possible that decreasing target space has a retrograde effect on developing thalamic neurons (Cunningham et al., 1987; Rennie et al., 1994; Lotto and Price, 1995; for review, see Oppenheim, 1999), and increases cell death in the thalamus, this would not explain the decrease in size of the superior colliculus, which does not project directly to the cortex. However, because the thalamus has decreased in size and is a target for a number of collicular projections, there may have been a retrograde effect on developing collicular neurons promoting increased cell death within the colliculus.

\section{Conclusions}

The present results demonstrate that the location of a cortical field is not strictly dependent on a predetermined location on the neuroepithelial sheet. Second, and equally important, very simple changes in the developing nervous system, such as changes in the size of the cortical sheet, can trigger a cascade of events that alter the rest of the nervous system in a manner consistent with what we observe in mammals with different sized brains.

One can assume that a simple change in the timing of horizontal proliferation of cells in the ventricular zone (Rakic, 1995a; Kornack and Rakic, 1998), or decreased cell death of progenitor cells (Kuida et al., 1998), could have significant consequences for the organization of the entire CNS. It is unknown whether such changes alone are sufficient to explain the emergence of new cortical fields. It is possible that an enlargement of the cortical sheet would simply result in larger cortical fields rather than more cortical fields. However, comparative studies demonstrate that the relationship between cortical sheet size and cortical field size is nonlinear. It is possible that enlargements of the cortical sheet, in addition to resulting in larger cortical fields, may also promote new interactions between thalamic inputs as well as corticocortical and interhemispheric interconnections (Krubitzer et al., 1998). Thus, combining retained elements in novel ways on a larger target may increase the information processing capacity of the cortex.

\section{REFERENCES}

Aitkin LM, Irvine DRF, Nelson JE, Merzenich MM, Clarey JC (1986) Frequency representation in the auditory midbrain and forebrain of a marsupial, the northern native cat (Dasyurus hallucatus). Brain Behav Evol 29:17-28.

Barbe MF, Levitt R (1995) Age-dependent specification of the corticocortical connections of cerebral grafts. J Neurosci 15:1819-1834.

Brodmann, K (1909) Vergleichende Lokalisationslehre der Grosshirnrinde in ihren Prinzipien dargestellt auf Grund des Zellenbaues. Leipzig: J. A. Barth.

Bulfone A, Smiga SM, Shimamura K, Peterson A, Puelles L, Rubenstein JLR (1995) T-Brain-1: a homolog of Brachyury whose expression defines molecularly distinct domains within the cerebral cortex. Neuron 15:63-78.

Carroll EW, Wong-Riley MTT (1984) Quantitative light and electron microscopic analysis of cytochrome oxidase-rich zones in the striate cortex of the squirrel monkey. J Comp Neurol 222:1-17.

Chang F-LF, Steedman JG, Lund RD (1986) The lamination and connectivity of embryonic cerebral cortex transplanted into newborn rat cortex. J Comp Neurol 244:401-411.

Chenn A, Braisted JE, McConnell SK, O'Leary DDM (1997) Development of the cerebral cortex: mechanisms controlling cell fate, laminar and areal patterning, and axonal connectivity. In: Molecular and cellular approaches to neural development (Cowan WM, Jessell TM, Sipursky SL, eds), pp 440-473. New York: Oxford UP.

Cohen-Tannoudji M, Babinet C, Marion W (1994) Early determination of a mouse somatosensory cortex marker. Nature 368:460-463.

Cowan WM, Fawcett JW, O'Leary DD, Stanfield BB (1984) Regressive events in neurogenesis. Science 225:1258-1265.

Cunningham TJ, Haun F, Chantler PD (1987) Diffusible proteins prolong survival of dorsal lateral geniculate neurons following occipital cortex lesions in newborn rats. Dev Brain Res 37:133-141.

DeHay C, Giroud P, Berland M, Smart I, Kennedy H (1993) Modulation of the cell cycle contributes to the parcellation of the primate visual cortex. Nature 366:464-466.

Erzurumlu RS, Jhaveri S (1995) Target influences on the morphology of trigeminal axons. Exp Neurol 135:1-16.

Erzurumlu RS, McKay RD, Jhaveri S (1994) Morphological specification of trigeminal neurites depends on target fields. Brain Res Dev Brain Res 83:132-137.

Ferri RT, Levitt P (1995) Regulation of region differences in the differentiation of cerebral cortical neurons by EGF family-matrix interactions. Development 21:1151-1160.

Frisén J, Yates PA, McLaughlin T, Friedman GC, O'Leary DDM, Barbacid M (1998) Ephrin-A5 (AL-1/RAGS) is essential for proper retinal axon guidance and topographical mapping in the mammalian visual system. Neuron 20:235-243.

Frost DO, Metin C (1985) Induction of functional retinal projections to the somatosensory system. Nature 317:162-164.

Gallyas F (1979) Silver staining of myelin by means of physical development. Neurology 1:203-209.

Gates GR, Aitkin LM (1982) Auditory cortex in the marsupial possum Trichosurus vulpecula. Hear Res 7:1-11.

Guilisano MV, Broccoli V, Pardini C, Boncinelli E (1996) Emx1 and Emx2 show different patterns of expression during proliferation and differentiation of the developing cerebral cortex in the mouse. Eur J Neurosci 8:1037-1050.

Huffman K, Molnár Z, Van Dellen A, Krubitzer LA (1998) Formation of cortical maps on a reduced cortical sheet. Soc Neurosci Abstr 24:59.

Huffman KJ, Nelson J, Clarey J, Krubitzer L (1999) Organization of somatosensory cortex in three species of marsupials, Dasyurus hallucatus, Dactylopsila trivirgata, and Monodelphis domestica: neural correlates of morphological specializations. J Comp Neurol 403:5-32.

Kaas JH (1982) The segregation of function in the nervous system: why do the sensory systems have so many subdivisions? Contrib Sens Physiol 7:201-240.

Kaas JH (1988) Why does the brain have so many visual areas? J Cognit Neurosci 1:121-135.

Kaas JH (1989) The evolution of complex sensory systems in mammals. J Exp Biol 146:165-176.

Kaas JH (1991) Plasticity of sensory and motor maps in adult mammals. Annu Rev Neurosci 14:137-167.

Kaas JH (1993) Evolution of multiple areas and modules within neocortex. Perspect Dev Neurobiol 1:101-107.

Kahn DM, Huffman KJ, Le C, Krubitzer L (1998) Retinal projections in a South American marsupial. Soc Neurosci Abstr 24:1393.

Kahn DM, Slutsky DA, Krubitzer LA (1999) Receptive field organization of primary visual cortex in a metatherian mammal (Monodelphis domestica). Soc Neurosci Abstr 25:1931.

Killackey HP (1990) Neocortical expansion: an attempt toward relating phylogeny and ontogeny. J Cognit Neurosci 2:1-17.

Killackey HP, Chiaia NL, Bennett-Clarke CA, Eck M, Rhoades RW (1994) Peripheral influences on the size and organization of somatotopic representations in the fetal rat cortex. J Neurosci 14:1496-1506.

Kornack DR, Rakic P (1998) Changes in cell-cycle kinetics during the development and evolution of the primate neocortex. Proc Natl Acad Sci USA 95:1242-1246.

Krubitzer L (1995) The organization of neocortex in mammals: are species differences really so different? Trends Neurosci 18:408-417.

Krubitzer L (1998) What can monotremes tell us about brain evolution? Philos Trans R Soc Lond B Biol Sci 353:1127-1146.

Krubitzer L (1999) How does evolution build a complex brain? In: Evolutionary developmental biology of the cerebral cortex (Bock G, Cardew G, eds). Novartis Foundation Symposium.

Krubitzer LA, Calford MB, Schmid LM (1993) Connections of somatosensory cortex in megachiropteran bats: the evolution of cortical fields in mammals. J Comp Neurol 327:473-506. 
Krubitzer L, Huffman K, Molnár Z (1998) Constructing the neocortex: influences on the pattern of organization in mammals In: Brain and mind: evolutionary perspectives (Gazzaniga MS, Altman J, eds), pp 19-34. Strasbourg: Human Frontier Science Program.

Kuida K, Haydar T, Kuan C-Y, Gu Y, Taya C, Karasuyama H, Su MS-S, Rakic P, Flavell RA (1998) Reduced apoptosis and cytochrome c-mediated caspase activation in mice lacking caspase 9. Cell 94:325-337.

Levitt P, Ferri R, Eagleson K (1995) Molecular contributions to cerebral cortical specification. In: Development of the cerebral cortex (Ciba Foundation Symposium) (Bock GR, Cardew G, eds), pp 203-213. Chichester: Wiley.

Levitt P, Barbe MF, Eagleson KL (1997) Patterning and specification of the cerebral cortex. Annu Rev Neurosci 20:1-24.

Lillien L (1998) Neural progenitors and stem cells: mechanisms of progenitor heterogeneity. Curr Opin Neurobiol 8:37-44.

Ling C, Jhaveri S, Schneider GE (1997) Target as well as source-derived factors direct the morphogenesis of anomalous retino-thalamic projections. J Comp Neurol 388:454-466.

Lotto RB, Price DJ (1995) The stimulation of thalamic neurite outgrowth by cortex-derived growth factors in vitro: the influence of cortical age and activity. Eur J Neurosci 7:318-328.

Manger P, Sum M, Szymanski M, Ridgway S, Krubitzer L (1998) Modular subdivisions of dolphin insular cortex: does evolutionary history repeat itself. J Cognit Neurosci 10:153-156.

Mann F, Zhukareva Z, Pimenta A, Levitt P, Bolz J (1998) Membraneassociated molecules guide limbic and nonlimbic thalamocortical projections. J Neurosci 18:9409-9419.

Merzenich MM, Nelson RJ, Kaas JH, Stryker MP, Jenkins WM, Sook JM, Cynader MS, Schoppmann A (1987) Variability in hand surface representations in areas $3 \mathrm{~b}$ and 1 in adult owl and squirrel monkeys. J Comp Neurol 258:281-296.

Merzenich MM, Grajski KA, Jenkins WM, Recanzone GH, Peterson B (1991) Functional cortical plasticity. Cortical network origins of representation changes. Cold Spring Harb Symp Quant Biol 55:873-887.

Miyashita-Lin EM, Hevner R, Wassarman KM, Martinez S, Rubenstein J (1999) Neocortical regionalization in the absence of thalamic innervation. Science 285:906-909.

Molnár Z, Blakemore C (1991) Lack of regional specificity for connections formed between thalamus and cortex in coculture. Nature 351:475-477.

Molnár Z, Blakemore C (1995) How do thalamic axons find their way to the cortex? Trends Neurosci 18:389-397.

Molnár Z, Blakemore C (1999) Development of signals influencing the growth and termination of thalamocortical axons in organotypic culture. Exp Neurol 156:363-393.

Molnár Z, Knott GW, Blakemore C, Saunders NR (1998) Development of thalamocortical projections in the South American grey short-tailed opossum (Monodelphis domestica). J Comp Neurol 398:491-514.

O'Leary DDM (1989) Do cortical areas emerge from a protocortex? Trends Neurosci 12:400-406.

O'Leary DDM, Schlaggar BL, Tuttle R (1994) Specification of neocortical areas and thalamocortical connections. Annu Rev Neurosci 17:419-439.

O'Leary DDM, Yates PA, McLaughlin T (1999) Molecular development of sensory maps: representing sights and smell in the brain. Cell 96:255-269.

Oppenheim RW (1999) Programmed cell death. In: Fundamental neuroscience (Zigmond MJ, Bloom FE, Roberts JL, Landis SC, Squire LR, eds), pp 581-609. San Diego: Academic.

Pallas SL, Sur M (1993) Visual projections induced into the auditory pathway of ferrets: II. Corticocortical connections of primary auditory cortex. J Comp Neurol 337:317-333.
Pallas SL, Roe AW, Sur M (1990) Visual projections induced into the auditory pathway of ferrets. I. Novel inputs to primary auditory cortex (AI) from the LP/pulvinar complex and the topography of the MGN-AI projection. J Comp Neurol 298:50-68.

Polleux F, DeHay C, Kennedy H (1997a) The timetable of laminar neurogenesis contributes to the specification of cortical areas in mouse neocortex. J Comp Neurol 385:95-116.

Polleux F, DeHay C, Moraillon B, Kennedy H (1997b) Regulation of neuroblast cell-cycle kinetics plays a crucial role in the generation of unique features of neocortical areas. J Neurosci 17:7763-7783.

Rakic P (1988) Specification of cerebral cortical areas. Science 241:170-176.

Rakic P (1995a) A small step for the cell, a giant leap for mankind: a hypothesis of neocortical expansion during evolution. Trends Neurosci 18:383-388.

Rakic P (1995b) Radial versus tangential migration of neuronal clones in the developing cerebral cortex. Proc Natl Acad Sci USA 92:11323-11327.

Rennie S, Lotto RB, Price DJ (1994) Growth-promoting interactions between the murine neocortex and thalamus in organotypic co-cultures. J Neurosci 61:547-564.

Richards LJ, Koester SE, Tuttle R, O'Leary DDM (1997) Directed growth of early cortical axons is influenced by a chemoattractant released from an intermediate target. J Neurosci 17:2245-2458.

Ridgway SH (1986) Dolphin brain size. In: Research on dolphins (Bryden MM, Darrison RJ, eds), pp 59-70. Oxford: Oxford UP.

Roe AW, Pallas SL, Hahm JO, Sur M (1990) A map of visual space induced in primary auditory cortex. Science 250:818-820.

Roe AW, Pallas SL, Kwon YH, Sur M (1992) Visual projections routed to the auditory pathway in ferrets: receptive fields of visual neurons in primary auditory cortex. J Neurosci 12:3651-3664.

Rosa MGP, Krubitzer LA, Molnár Z, Nelson JE (1999) Organization of visual cortex in the northern quoll, Dasyurus hallucatus: evidence for a homologue of the second visual area in marsupials. Eur J Neurosci 11:907-915.

Rubenstein JLR, Beachy PA (1998) Patterning of the embryonic forebrain. Curr Opin Neurobiol 8:18-26.

Schlaggar BL, O'Leary DDM (1991) Potential of visual cortex to develop an array of functional units unique to somatosensory cortex. Science 252:1556-1560.

Sperry RW (1963) Chemoaffinity in the orderly growth of nerve fiber patterns and connections. Proc Natl Acad Sci USA 50:703-710.

Stephan H, Baron G, Frahm HD (1988) Comparative size of brains and brain components. Comp Primate Biol 4:1-38.

Suzuki SC, Inoue T, Kimura Y, Tanaka T, Takeichi M (1997) Neuronal circuits are subdivided by differential expression of type-II classic cadherins in postnatal mouse brains. Mol Cell Neurosci 9:433-447.

Turlejski K, Djavadian RL, Saunders NR (1994) Projection of visuotopically organized afferents to the dorsal thalamus on the opossum, Monodelphis domestica. Acta Neurobiol Exp 54:307-319.

Walsh C, Cepko CL (1992) Widespread dispersion of neuronal clones across functional regions of the cerebral cortex. Science 255:434-440.

Walsh C, Cepko CL (1993) Clonal dispersion in proliferative layers of developing cerebral cortex. Nature 362:632-635.

Windrem MS, Finlay BL (1991) Thalamic ablations and neocortical development: alterations of cortical cytoarchitecture and cell number. Cereb Cortex 1:230-240.

Wray GA (1994) Developmental evolution: new paradigms and paradoxes. Dev Genet 15:1-6.

Zilles K, Wree A (1995) Cortex: areal and laminar structure. In: The rat nervous system, Ed 2 (Paxinos G, ed), pp 649-685. San Diego: Academic. 